INOVASI IMPLEMENTASI E-HEALTH

\title{
SEBAGAI MANIFESTASI SMART CITY DI KOTA YOGYAKARTA UNTUK MENINGKATKAN KUALITAS PELAYANAN KESEHATAN IBU DAN ANAK
}

\author{
Erni Saharuddin ${ }^{1}$
}

\begin{abstract}
The high public demand for quality improvement on KIA becomes the basic fundamentals for the government of Yogyakarta to upgrade the quality and efficiency of KIA services. One of the implemented policies is the application of smart city in the health sector, primarily focusing on e-Health development. This research aims reviewing innovation in the implementation of e-Health in health centers Mantrijeron by employing a qualitative approach with interviews, observation, and documentation. The results showed that innovation of e-Health was divided into four categories: man, money, methods and machine. In terms of man (human resources) there were Simpus facilitation officer and adequate number of qualified human resources. Meanwhile money innovation occurred by adequate financial support from APBD, BOK and BLUD budget. Method innovation came in with the application of SOP in each service which also describes the associated use of Simpus. Machine innovation occurred through adequate computer devices, efforts to restore the hardware restoration efforts, routine network maintenance by a team of Service Level Agreement (SLA) and assistance from the Department of Communications, Information and Coding of Yogyakarta City.
\end{abstract}

Keywords: e-Health, SIMPUS, Innovation, Service Quality

\begin{abstract}
ABSTRAK
Tingginya tuntutan publik akan peningkatan kualitas pelayanan Kesehatan Ibu dan Anak (KIA) menjadi dasar bagi Pemerintah Kota Yogyakarta untuk melakukan peningkatan kualitas dan efisiensi pelayanan. Salah satunya dengan penerapan smart city di bidang kesehatan dengan fokus pengembangan e-Health. Penelitian ini mengkaji inovasi yang dilakukan Puskesmas Mantrijeron dalam penerapan e-Health. Menggunakan pendekatan kualitatif dengan metode wawancara, observasi, dan dokumentasi. Hasil penelitian menunjukkan inovasi bidang man; adanya pendampingan kepada petugas Simpus, serta kualitas SDM yang memadai, money; dukungan anggaran memadai berasal dari dana APBD, BOK dan BLUD; methods; adanya SOP di masing-masing bidang pelayanan yang di dalamnya menjelaskan terkait penggunaan Simpus, pembentukan tim SIK untuk mendukung Simpus. Machine; perangkat komputer yang memadai, dilakukan pembaharuan hardware, perawatan jaringan oleh tim Service Level Agreement (SLA) dan bantuan dari Dinas Komunikasi, Informatika dan Persandian Kota Yogyakarta.
\end{abstract}

Kata Kunci: $e$-Health, SIMPUS, Inovasi, Kualitas Pelayanan

\footnotetext{
${ }^{1}$ Dosen, Administrasi Publik, Universitas ‘Aisyiyah Yogyakarta. email: ernisaharuddin263@gmail.com
} 


\section{PENDAHULUAN}

Angka kematian ibu dan bayi (AKI dan AKB) di Kota Yogyakarta menunjukkan trend yang fluktuatif dari tahun 2009 hingga 2014. Data Profil Kesehatan tahun 2015 Kota Yogyakarta menunjukkan bahwa angka kematian ibu mengalami kenaikan dan penurunan yang tajam dari tahun 2009 hingga 2014. Sedangkan angka kematian bayi menunjukkan trend kenaikan sebesar 1,622 per 1.000 kelahiran hidup dari tahun 2009 hingga 2014 (Profil Kesehatan Kota Yogyakarta Tahun 2015). Kenaikan trend AKI dan AKB ini menjadi sebuah hal yang problematis karena cakupan persalinan yang ditolong oleh tenaga kesehatan sebesar 99.89\%. Angka ini jauh di atas SPM Nasional sebesar 95\%. Menurut hasil penelitian pusat Kebijakan dan Manajemen Kesehatan (PKMK), Fakultas Kedokteran UGM, 60\% kematian ibu tersebut umumnya disebabkan keterlambatan rujukan.

Semakin besarnya kompleksitas dampak dari masalah keterlambatan rujukan dan tingginya tuntutan publik akan peningkatan kualitas pelayanan kesehatan ibu dan anak, menjadi dasar bagi Pemerintah Kota Yogyakarta untuk melakukan peningkatan kualitas dan efisiensi pelayanan. Salah satu upaya kebijakan yang dilakukan adalah penerapan smart city di bidang kesehatan dalam bentuk smart healthcare, dengan fokus pengembangan $e$-Health di berbagai instansi kesehatan, seperti rumah sakit pemerintah, swasta, dan Puskesmas.

Sebagai sebuah strategi yang dijalankan untuk meningkatkan efisiensi pelayanan kesehatan, khususnya untuk menekan permasalahan keterlambatan rujukan, e-Health diharapkan mampu berkontribusi positif bagi peningkatan kualitas pelayanan kesehatan ibu dan anak, misalnya kecepatan dalam pelayanan di pendaftaran maupun di bagian poli dalam pencatatan dan pencarian data pasien. Namun, nampaknya penerapan e-Health masih menemui beberapa tantangan, seperti kualitas infrastruktur dan sumber daya manusia yang kurang memadai, belum adanya inter-operationability yang baik dan berbagai persoalan tata kelola lainnya.

Anomali terjadi di Puskesmas Mantrijeron, Kota Yogyakarta. Di tengah besarnya tantangan pengembangan $e$ Health, Puskesmas Mantrijeron justru menjadi salah satu Puskesmas percontohan bagi Puskesmas lainnya. Puskesmas ini memperoleh akreditasi dengan nilai paripurna. Berdasarkan penuturan Kepala Puskesmas, efektivitas 
penerapan $e$-Health ini tidak dapat dipisahkan dari aspek inovasi berbasis IPTEK yang senantiasa dikembangkan secara periodik dengan dukungan kualitas SDM yang baik.

Dalam penelitian ini Puskesmas Mantrijeron akan menjadi lokus penelitian untuk melihat best practice dari berbagai inovasi yang dilakukan, sehingga Puskesmas Mantrijeron dapat menjalankan konsep e-Health secara optimal. Puskesmas Mantrijeron adalah Puskesmas percontohan di DIY, sehingga hasil penelitian ini akan bermanfaat bagi pengembangan $e$-Health di berbagai Puskesmas lainnya, terutama dalam upaya peningkatan kualitas pelayanan kesehatan ibu dan anak dan efisiensi pelayanan kesehatan lainnya.

$$
\text { Sehingga dapat dirumuskan }
$$
masalah, yaitu: pertama, bagaimana aspek inovasi dalam implementasi $e$-Health di Puskesmas Mantrijeron Yogyakarta terutama untuk meningkatkan kualitas pelayanan ibu dan anak? Kedua, faktor pendukung dan penghambat apa saja yang mempengaruhi pengembangan $e$-Health $\mathrm{di}$ Puskesmas Mantrijeron?

Sehingga penelitian ini diharapkan dapat mendeskripsikan aspek inovasi dalam implementasi e-Health di Puskesmas Mantrijeron terutama untuk meningkatkan kualitas pelayanan kesehatan ibu dan anak. Dan juga dapat mengidentifikasi faktor pendukung dan penghambat yang mempengaruhi inovasi pengembangan $e$-Health di Puskesmas Mantrijeron.

\section{Implementasi $\boldsymbol{e}$-Health}

Implementasi $e$-Health terdiri dari dua (2) konsep utama, yaitu konsep implementasi kebijakan dan e-Health. Konsep implementasi kebijakan menjadi konsep untuk menerangkan dinamika penerapan konsep $e$-Health. Implementasi kebijakan secara umum berisi mengenai penjelasan berbagai variabel yang terkait dengan proses penerapan kebijakan publik, sedangkan implementasi $e$-Health adalah bagian dari konsep implementasi kebijakan smart city di bidang kesehatan.

\section{Implementasi Kebijakan Publik}

Implementasi kebijakan pada prinsipnya adalah cara agar sebuah kebijakan dapat mencapai tujuannya. Van Meter dan Van Horn (dalam Budi Winarno, 2008:146-147) mendefinisikan implementasi kebijakan publik sebagai tindakan-tindakan dalam keputusankeputusan sebelumnya. Tindakantindakan ini mencakup usaha-usaha untuk mengubah keputusan-keputusan menjadi tindakan-tindakan operasional dalam 
kurun waktu tertentu maupun dalam rangka melanjutkan usaha-usaha untuk mencapai perubahan besar dan kecil yang ditetapkan oleh keputusan-keputusan kebijakan yang dilakukan oleh organisasi publik yang diarahkan untuk mencapai tujuan-tujuan yang telah ditetapkan.

Adapun makna implementasi menurut Daniel A. Mazmanian dan Paul Sabatier (1979) sebagaimana dikutip dalam buku Solihin Abdul Wahab (2008: 65), mengatakan bahwa implementasi adalah memahami apa yang senyatanya terjadi sesudah suatu program dinyatakan berlaku atau dirumuskan. Fokus perhatian implementasi kebijaksanaan yakni kejadian-kejadian dan kegiatan-kegiatan yang timbul sesudah disahkannya pedoman-pedoman kebijaksanaan negara yang mencakup baik usaha-usaha untuk mengadministrasikannya maupun untuk menimbulkan akibat atau dampak nyata pada masyarakat atau kejadian-kejadian.

\section{Konsep e-Health}

Definisi formal $e$-Health dapat ditemui antara lain sebagaimana diajukan oleh World Health Organization (WHO), yaitu penggunaan teknologi dan informasi dalam bidang kesehatan untuk melayani pasien, riset, pendidikan, mendiagnosis penyakit dan memonitor kesehatan publik. Sementara dalam KepMenKes Nomor
192/MENKES/SK/VI/2012 disebutkan bahwa $e$-Health adalah pemanfaatan TIK di sektor kesehatan terutama untuk meningkatkan pelayanan kesehatan.

e-Health memiliki cakupan yang lebih luas dari sekedar layanan kesehatan online. Semua teknologi informasi dan komputer yang diterapkan di bidang kesehatan adalah e-Health. Dengan kata lain, e-Health adalah salah satu bentuk penerapan teknologi, informasi, dan komputer di bidang kesehatan. Penerapan teknologi ini lebih menekankan pada peningkatan aksesibilitas, efisiensi, efektifitas, dan kualitas proses klinis dan bisnis dalam organisasi, praktisi, pasien, dan konsumen di bidang kesehatan.

Dalam proses implementasi, $e$ Health seringkali menghadapi beberapa kendala, seperti kesiapan sumber daya manusia, kesiapan organisasi yang terlibat, budaya kerja, perkembangan teknologi dan ketersediaan infrastruktur dan lain sebagainya. Oleh karena itu, diperlukan daya kreasi melalui inovasi dan peningkatan kualitas sumber daya yang baik untuk menjamin kelancaran implementasi e-Health di lapangan. Dalam penelitian ini $e$-Health dilihat sebagai manifestasi penerapan konsep smart city di bidang kesehatan. e-Health dilihat sebagai konsep yang diterapkan 
untuk meningkatkan efisiensi dan kualitas pelayanan kesehatan ibu dan anak.

\section{Aspek Inovasi dalam Implementasi $e$ - health}

Penerapan E-Health ini merupakan salah satu contoh munculnya inovasi dalam bidang kesehatan. Menurut Amabile, inovasi berasal dari kata innovare, yaitu istilah dalam Bahasa Latin yang berarti "Penggunaan suatu cara atau sarana yang baru guna menghasilkan nilai yang baru." Inovasi adalah memperkenalkan ide baru, barang baru, pelayanan baru dan cara-cara baru yang lebih bermanfaat (Amabile, 1996). Ernita membagi jenis inovasi menjadi 4 jenis, yaitu penemuan, pembangunan, duplikasi, dan sintesis.

Tujuan yang diharapkan dari inovasi salah satunya adalah peningkatan kualitas. Menurut Ishikawa, kualitas pelayanan dapat ditingkatkan dengan menerapkan berbagai inovasi di bidang man, money, methods dan machine. Man merujuk pada sumber daya manusia yang dimiliki oleh organisasi. Dalam manajemen, faktor manusia adalah faktor yang paling menentukan. Manusia yang membuat tujuan dan manusia pula yang melakukan proses untuk mencapai tujuan. Money merupakan salah satu unsur yang tidak dapat diabaikan, karena segala sesuatu harus diperhitungkan secara rasional. Uang sebagai sarana manajemen harus digunakan sedemikian rupa agar tujuan yang diinginkan tercapai, kegiatan manajemen dipengaruhi oleh pengelolaan keuangan. Method digunakan untuk melakukan kegiatan secara guna dan berhasil guna manusia dihadapkan kepada berbagai alternatif metode cara menjalankan pekerjaan tersebut sehingga cara yang dilakukannya dapat menjadi sarana atau alat manajemen untuk mencapai tujuan. Sedangkan machine merujuk pada infrastruktur atau sarana dan prasarana yang dimiliki oleh sebuah organisasi. Sarana dan prasarana ini menjadi fondasi dasar bagi pelaksanaan program dan kegiatan organisasi.

\section{METODE}

Penelitian ini fokus pada Puskesmas Mantrijeron dengan menggunakan pendekatan deskriptif kualitatif. Peneliti menggunakan wawancara, observasi, dan studi dokumentasi sebagai instrumen pengumpulan data. Adapun pihak-pihak yang menjadi informan dalam penelitian ini adalah petugas Simpus, petugas SLA, pegawai bagian layanan pendaftaran, bidang rekam medis, petugas bagian laboratorium, Bidan poli KIA, masyarakat pengguna layanan KIA dan petugas di bagian kasir. 
Teknik analisis data dalam penelitian ini merujuk pada teori yang dikemukakan oleh Huberman dan Miles dalam Idrus (2009) mengajukan model analisis data yang disebut dengan model interaktif. Pertama dengan melakukan reduksi data; data yang telah dikumpulkan dari lapangan melalui wawancara direduksi dengan cara merangkum, memilih hal-hal yang pokok dan penting, mengklasifikasikan sesuai fokus yang ada pada masalah dalam penelitian ini. Untuk validasi, digunakan teknik triangulasi dengan sumber, yaitu dengan membandingkan dan mengecek balik derajat kepercayaan suatu informasi yang diperoleh, dilanjutkan dengan penyajian data, kemudian analisis pada bagian pembahasan mengenai inovasi dalam implementasi e-Health di Kota Yogyakarta serta penarikan kesimpulan.

\section{HASIL DAN PEMBAHASAN \\ e-health di Puskesmas Mantrijeron}

Berkembangnya teknologi informasi dan komunikasi yang semakin pesat, sehingga mendorong adanya inovasi dan perubahan yang melibatkan eksperimen dalam berbagai bidang kesehatan yang menerapkan penggunaan komputer dalam kegiatannya. e-health yang diartikan sebagai penggunaan teknologi, informasi, dan komunikasi termasuk pula elektronika, telekomunikasi, komputer, dan informatika untuk memproses berbagai jenis informasi, hal ini sesuai dengan KepMenKes Nomor 192/MENKES/SK/VI/2012 disebutkan bahwa $e$ Health adalah pemanfaatan TIK di sektor kesehatan terutama untuk meningkatkan pelayanan kesehatan.

Pemanfaatan e-Health di Puskesmas Mantrijeron mulai digunakan sejak tahun 2005, yang dikenal dengan istilah Simpus. Puskesmas Mantrijeron menggunakan Simpus yang diinisiasi oleh dr. Willy dengan menggunakan aplikasi Windows, berbeda halnya dengan Dinas Kesehatan Kota Yogyakarta yang baru mulai mencanangkan pemanfaatan Simpus ini di tahun 2009 dengan aplikasi Linux. Dengan adanya Simpus yang diinisiasi oleh Dinas Kesehatan Kota Yogyakarta maka mau tidak mau pihak Puskesmas harus mengikuti karena perbedaan aplikasi yang digunakan. Akan tetapi, Simpus pada saat itu hanya diterapkan di bagian pendaftaran pasien, sementara untuk di masing-masing poli belum menggunakan Simpus. Penerapan Simpus di masing-masing poli baru dimaksimalkan pada tahun 2012.

Di Puskesmas Mantrijeron penerapan $e$-Health atau Simpus sekarang 
ini dapat pula dilihat dari sistem antrian pasien yang sudah menggunakan mesin antrian. Dengan urutan; pasien datang lalu mengambil nomor antrian dengan menekan tombol pada layar dan memilih poli yang akan dituju. Selanjutnya untuk registrasi pasien, pasien akan menunjukkan kartu berobat dan oleh petugas bagian pendaftaran akan menempelkan barcode yang tertera pada kartu berobat dan secara otomatis data pasien akan muncul di layar komputer.

Pasien kemudian menuju ke Poli yang dituju. Untuk pelayanan KIA pasien akan antri, dan setelah diperiksa dokter/bidan akan menuliskan hasil pemeriksaan pada buku rekam medis pasien. Selanjutnya petugas rekam medis (pengelola Simpus) akan menginput data rekam medis pasien yang masuk pada hari tersebut. Penginputan data rekam medis pasien ini dilakukan setiap hari melalui sistem komputerisasi. Selain secara manual melalui buku rekam medis, juga sudah melalui media komputer.

Penerapan $e$-Health lainnya adalah pada sistem rujukan online bagi penerima jaminan kesehatan. Aplikasi untuk rujukan online ini telah terkoneksi dengan pemberi jaminan kesehatan seperti BPJS, dan Rumah Sakit yang menjadi mitra Puskesmas. Sementara pasien yang tidak mendapat jaminan kesehatan, sistem rujukan pasien masih dilakukan secara manual.

e-Health juga dapat dilihat pada sistem pelaporan. Hal ini utamanya ketika pihak Dinas Kesehatan Kota Yogyakarta memerlukan laporan dari Puskesmas Mantrijeron, maka Dinas Kesehatan Kota Yogyakarta akan membuka Simpus Puskesmas Mantrijeron. Beda halnya ketika masih menggunakan laporan tertulis petugas Simpus Mantrijeron tiap bulan harus menyetorkan laporan secara langsung ke Dinas Kesehatan melalui email. Dengan adanya e-Health ini maka waktu pelaporan tidak lagi menjadi kendala, Dinas Kesehatan Kota Yogyakarta bisa mengambil data atau laporan yang dibutuhkan kapan saja melalui Simpus ini.

\section{Inovasi Implementasi $\boldsymbol{e}$-health sebagai Manifestasi Smart City Di Kota Yogyakarta khususnya Di Puskesmas Mantrijeron}

$\begin{array}{rcc}\text { Konsep smart city yang } \\ \text { dikembangkan } & \text { pemerintah } & \text { Kota }\end{array}$
Yogyakarta mengacu pada inovasi bidang teknologi informasi yang pada tahun 2015 berhasil meraih penghargaan best of the best IDSA dalam ajang Indonesia Digital Society Award (IDSA) salah satunya di bidang kesehatan. Pengembangan 
teknologi informasi yang menjadi unggulan di sektor kesehatan adalah pengembangan Sistem Informasi Manajemen (SIM) Puskesmas sebagai bentuk pengembangan $e$-Health.

Puskesmas Mantrijeron sebagaimana yang telah diuraikan sebelumnya bahwa Puskesmas ini telah menunjukkan adanya penerapan Simpus mulai dari bagian pendaftaran, poli, rekam medis pasien, rujukan online, hingga pelaporan. Puskesmas Mantrijeron sejauh ini sebagai Puskesmas percontohan terus meningkatkan kualitas pelayanannya dan hal ini tentunya tidak terlepas dari berbagai inovasi-inovasi yang dilakukan untuk mendukung pelaksanaan e-Health tersebut. Menurut Ishikawa, kualitas pelayanan dapat ditingkatkan dengan menerapkan berbagai inovasi di bidang man, money, methods dan machine. Di bawah ini akan dijelaskan lebih lanjut inovasi di masing-masing bidang tersebut yang telah dilakukan oleh Puskesmas Mantrijeron.

\section{Inovasi Bidang Sumber Daya Manusia}

Man merujuk pada sumber daya manusia yang dimiliki oleh organisasi. Dalam manajemen faktor manusia adalah faktor yang paling menentukan. Manusia yang membuat tujuan dan manusia pula yang melakukan proses untuk mencapai tujuan.

Dukungan SDM untuk pengelola Simpus khususnya di bagian rekam medis pasien di Puskesmas Mantrijeron sudah memadai dengan jumlah tiga (3) orang, begitu juga dengan pengetahuan dan keterampilan yang dimiliki oleh pegawai telah mendukung untuk pelaksanaan tugasnya seperti pengetahuan pengoperasian Simpus, pengetahuan dalam pembuatan laporan yang terkoneksi dengan Dinas Kesehatan Kota Yogyakarta, pengetahuan perawatan jaringan, dan lain sebagainya. Di bagian pelayanan pendaftaran SDM dengan jumlah tiga (3) pegawai juga sudah memadai untuk pelaksanaan tugasnya, hal ini didukung dengan keterampilan para pegawai dalam menggunakan komputer.

Untuk pengembangan e-Health khususnya pada sistem kasir ditemui persoalan terkait kurangnya SDM, pegawai yang bertugas hanya satu (1) orang, sehingga terkadang pegawai di layanan pendaftaran juga ikut membantu. Walaupun di bagian ini masih menggunakan sistem manual akan tetapi untuk mendukung pengembangan $e$ Health kedepannya diperlukan penambahan SDM. 
Pengembangan pegawai di Puskesmas Mantrijeron sendiri. Pada Puskesmas Mantrijeron dalam bentuk tahun 2005 oleh dr. Willy dibuat Simpus pelatihan sudah dilakukan yaitu berupa pendampingan kepada petugas Sistem Informasi Puskesmas yang pada saat itu diwakili oleh Bapak Lukiman, selain itu di Puskesmas ini dengan metode belajar dari pegawai lainnya yang lebih paham ternyata mampu membantu dalam pelaksanaan tugas-tugas para pegawai. Hal ini sesuai dengan wawancara dengan Ibu Rini:

"Tapi kalau tidak paham ditanyakan sama yang lebih paham Mbak Hesti atau Pak Lukiman." (Hasil wawancara tanggal 1 Maret 2017)

Di awal pengenalan Simpus oleh Pemerintah Dinas Kesehatan Kota Yogyakarta pihak dinas telah memberikan pendampingan kepada perwakilan Puskesmas termasuk Puskesmas Mantrijeron. Hal yang berbeda di Mantrijeron dalam penggunaan Simpus adalah karena jauh sebelum Pemerintah Dinas Kesehatan Kota Yogyakarta menginstruksikan kepada Puskesmas untuk menggunakan Simpus, Puskesmas Mantrijeron justru sudah menggunakan Simpus yang merupakan buatan Puskesmas Mantrijeron walaupun bentuknya saat itu masih sangat sederhana dan hanya digunakan pada bagian pendaftaran. Sehingga pegawai Puskesmas khususnya yang mengelola Simpus tidak merasa terbebani dengan instruksi dari Dinas Kesehatan Kota Yogyakarta, hanya saja perlu beradaptasi dengan Simpus baru yang dibuat oleh Dinas Kesehatan Kota Yogyakarta.

\section{Inovasi Bidang Keuangan}

Salah satu pengertian inovasi adalah pembangunan yakni pengembangan dari suatu produk pelayanan atau proses yang sudah ada. Dalam bidang keuangan terus dilakukan pembaharuan perencanaan keuangan khususnya yang mendukung pelaksanaan Simpus. Pada tahun 2017 total anggaran yang disediakan untuk membiayai kegiatan operasional di Puskesmas Mantrijeron adalah 1,8 M. Untuk dukungan pemeliharaan dan pengadaan perangkat yang mendukung e-Health diuraikan sebagai berikut: 
Tabel 1. Dukungan Anggaran yang Mendukung e-Health Tahun 2017 di Puskesmas Mantrijeron

\begin{tabular}{|l|c|c|}
\hline \multicolumn{1}{|c|}{ Kebutuhan } & Total Anggaran & Sumber Dana \\
\hline Pengadaan Komputer & 18.000 .000 & BLUD \\
\hline $\begin{array}{l}\text { Pemeliharaan dan suku } \\
\text { cadang }\end{array}$ & 20.080 .000 & BLUD \\
\hline
\end{tabular}

Sumber: Data Sekunder Rincian Anggaran Puskesmas Mantrijeron Tahun 2017.

Hal ini dinilai memadai karena kualitas dalam pelaksanaan pekerjaan selain sumber dana dari BLUD. Dukungan sehingga berdampak pada peningkatan keuangan lainnya bersumber dari APBD dan Bantuan Operasional Kesehatan kualitas pelayanan.

Seperti yang telah dijelaskan (BOK). Hal ini juga didukung dari pendapat Ibu Hesti:

"Kalau biaya terkait Simpusnya sendiri yang mengelola kan dinas sementara kalau ada penambahan perangkat komputer atau apapun itu kami tinggal mengusulkan saja, kalau minta biaya itu insya allah dipenuhi selama itu mendukung untuk pekerjaan kami tinggal mengusulkan saja ke bagian keuangan.” (Hasil wawancara tanggal 1 Maret 2017).

Komitmen ditunjukkan dengan kesiapan pendanaan dalam pengembangan sistem, hal ini dirasakan oleh para pegawai Puskesmas yang ketika membutuhkan anggaran senantiasa bisa dipenuhi untuk mendukung pelaksanaan tugas-tugasnya.

\section{Inovasi Bidang Metode}

Metode diartikan sebagai cara kerja yang mendukung pelaksanaan tugastugas. Inovasi dalam metode ini diperlukan agar terjadi peningkatan sebelumnya bahwa Simpus di Puskesmas Mantrijeron bukan hal yang baru lagi, berkat inisiatif dari Puskesmas Mantrijeron pada tahun 2005 dalam penggunaan Simpus. Saat ini penerapan Simpus di Puskesmas Mantrijeron didukung dengan adanya petugas Sistem Informasi Kesehatan (SIK) yang terdiri dari dua (2) orang petugas.

Untuk metode pelaksanaan Simpus di Puskesmas Mantrijeron, saat ini berdasarkan pada SOP di masing-masing bidang pelayanan. Di setiap bidang terdapat penjelasan terkait penggunaan Simpus. Hal ini sangat membantu dalam penggunaan Simpus di setiap bidangnya.

Mekanisme koordinasi dengan pegawai Puskesmas lainnya ataupun dengan pimpinan dilakukan pada kegiatan Apel pagi, group Whatsapp dan juga dalam bentuk rapat rutin yang dilaksanakan setiap bulan. Hal ini sangat 
membantu dalam pelaksanaan kegiatan di Puskesmas Mantrijeron.

\section{Inovasi Bidang Machine (Teknologi)}

Saat ini faktor teknologi memang menjadi suatu hal yang sangat dibutuhkan dalam menjalankan organisasi agar lebih efisien. Penggunaan teknologi di Puskesmas Mantrijeron tentu saja sangat diperlukan dalam mendukung e-Health. Di setiap bagian pelayanan di Puskesmas Mantrijeron baik itu pendaftaran, rekam medis, poli, laboratorium, dan farmasi sudah dilengkapi dengan perangkat Komputer. Di bagian pendaftaran saat ini juga sudah menggunakan mesin antrian dilengkapi dengan monitor yang lebih memudahkan masyarakat dalam menerima pelayanan.

Namun, tidak dipungkiri seringkali terjadi kerusakan perangkat komputer maupun jaringan. Terutama permasalahan di jaringan, misalnya jaringan tidak terkoneksi, Wi-fi nya mati, servernya mati. Di Puskesmas Mantrijeron sendiri sudah didukung dengan petugas Service Level Agreement Perangkat Komputer dan Koneksi Internet atau Intranet. Untuk penanganan pertama akan dilaporkan ke SLA ketika nantinya pengendali SLA tidak mampu memperbaiki baru kemudian dilaporkan ke Dinas Komunikasi Informatika dan Persandian Kota
Yogyakarta. Hal ini sesuai dengan penuturan Bapak Lukiman:

"Tim SLA di sini untuk penanganan pertama jadi kalau penangannan pertama itu nggak bisa kami langsung lapor ke TIT, Jadi tim SLA itu ada di bawah TIT kalau sekarang bukan TIT tapi di bawah Dinas Komunikasi, Informatika dan Persandian Kota Yogyakarta. Seperti kemarin saya laporkan ini harus diganti, karena kami tidak bisa menangani kami laporkan, laporannya tidak melalui surat tapi melalui grup Whatsapp." (Hasil wawancara 10 Februari 2017)

Dari penuturan Bapak Lukiman dapat dipahami bahwa untuk perawatan jaringan tidak lagi menjadi kendala bagi Puskesmas Mantrijeron karena didukung oleh petugas SLA dan juga TIT serta Dinas Komunikasi Informatika dan Persandian Kota Yogyakarta, komunikasi bisa terjalin dengan baik dan lebih mudah.

Untuk peningkatan spesifikasi komputer atau pembelian perangkat di Puskesmas Mantrijeron tidak serta merta mengganti dengan perangkat yang baru, akan tetapi tetap melalui perbaikan terlebih dahulu, dan jika nantinya akan melakukan pembelian perangkat komputer dan pendukungnya akan dikonsultasikan kepada Dinas Komunikasi Informatika dan Persandian Kota Yogyakarta. 


\section{Dampak Penggunaan e-Health Terhadap Kualitas Pelayanan Kesehatan Ibu Dan Anak di Puskesmas Mantrijeron}

Dengan penggunaan $e$-Health atau

Simpus di Puskesmas Mantrijeron telah membawa dampak tidak hanya dalam pelaksanaan tugas para pegawai yang lebih mudah dan lebih cepat, tetapi juga data yang disajikan semakin akurat, termasuk untuk rekam medis pasien. Hal ini sesuai dengan yang dikatakan Ibu Hesti:

"Dengan Simpus itu pekerjaan kami sudah berkurang karena dinas mau ngambil data apapun dari Simpus sudah bisa tanpa kami harus melaporkan yaa otomatis manfaatnya pengambilan dan penyajian data semakin cepat." (Hasil wawancara tanggal 1 Maret 2017).

Hal ini didukung oleh pendapat Bapak Lukiman:

"Untuk saya sendiri pekerjaan semakin cepat, data yang akan kami tampilkan semakin akurat, karena kalau yang masih manual itu kan kadang-kadang mau nulis 555555 kadang tertulis 6." (Hasil wawancara tanggal 10 Februari 2017).

Dampak lain yang dirasakan setelah penggunaan e-Health ini adalah jumlah rata-rata kunjungan pasien tiap harinya mengalami peningkatan. Pada saat pelaksanaan pekerjaan masih manual tiap harinya Puskesmas Mantrijeron melayani maksimal 150 pasien, tetapi setelah adanya $e$-Health atau Simpus ini jumlah pasien yang dilayani bertambah yaitu 200250 pasien. Untuk di layanan KIA juga demikian, pasien yang dilayani juga bertambah bisa mencapai 30 orang tiap kali jadwal kunjungan KIA.

Sebagaimana indikator dari kualitas pelayanan diantaranya adalah keandalan, baik dari segi waktu proses pelayanan, bagian pendaftaran, pengobatan dan keakuratan data yang disajikan. Dengan penggunaan Simpus dan mesin antrian di bagian pendaftaran ternyata lebih memudahkan masyarakat dilihat dari waktu layanan pendaftaran yang cepat. Begitu juga dengan waktu layanan di bagian pengobatan, adanya data rekam medis pasien membuat proses pelayanan semakin cepat, dan juga akurat sehingga memberikan kepuasan tersendiri bagi masyarakat.

Faktor pendukung dan penghambat dalam pengembangan e-Health di Puskesmas Mantrijeron

\section{Faktor Pendukung}

Keberhasilan Puskesmas Mantrijeron dalam mengembangkan $e$ Health memang bukan hal yang mudah untuk diraih. Faktor sumberdaya manusia yang memiliki keterampilan dan pengetahuan yang memadai sangat 
berkontribusi di dalamnya, selain itu juga didukung oleh pimpinan yang memiliki komitmen untuk terus mendukung kegiatan-kegiatan terutama dalam pengembangan Simpus. Dari pihak eksternal sendiri, adanya dukungan dari Dinas Kesehatan Kota Yogyakarta, Dinas Komunikasi Informatika, dan Persandian Kota Yogyakarta yang memberikan ruang komunikasi yang lebih mudah sehingga mempercepat ketika terjadi kendalakendala yang dihadapi oleh Puskesmas Mantrijeron.

\section{Faktor Penghambat}

Dalam pengembangan e-Health dalam hal ini Simpus tidak dipungkiri terdapat juga berbagai penghambat, seperti dari segi kuantitas untuk SDM di bagian kasir belum memadai sehingga untuk kedepannya untuk pengembangan Simpus di sistem kasir perlu ada penambahan SDM, penghambat atau kendala lainnya adalah persoalan jaringan yang seringkali eror terutama aplikasi pcare BPJS Kesehatan, hal ini disebabkan karena terlalu banyaknya pengguna aplikasi.

\section{SIMPULAN}

$$
\text { e-Health di Puskesmas }
$$

Mantrijeron berupa Simpus yang terdapat di masing-masing bidang pelayanan, baik itu di sistem antrian, rekam medis pasien, poli, dan laboratorium. Dalam pengembangan Simpus tersebut dilakukan berbagai inovasi yang mampu mendukung dalam pelaksanaannya, di bidang SDM dilakukan inovasi berupa pemberian pendampingan, metode belajar bersama yang dianggap efektif bisa membantu pegawai yang lainnya. Inovasi di bidang Keuangan terdapat berbagai dukungan anggaran baik itu dari BLUD, BOK dan juga APBD. BLUD sendiri diperoleh dari banyaknya kaji banding di Puskesmas Mantrijeron, dan kegiatan-kegiatan lainnya. Inovasi di bidang metode yang berkontribusi dalam pengembangan Simpus ini adalah adanya SOP di masingmasing bidang pelayanan yang di dalamnya juga menjelaskan terkait penggunaan Simpus, selain itu juga dengan dibentuknya tim Sistem Informasi Kesehatan (SIK) Puskesmas ternyata mampu memberikan kontribusi nyata dalam pengelolaan Simpus di Puskesmas Mantrijeron dalam mengkoordinasikan dan mengintegrasikan data-data Puskesmas Mantrijeron. Inovasi di bidang mesin di Puskesmas Mantrijeron berupa pengadaan perangkat komputer, perawatan jaringan, updating hardware, dan spesifikasi komputer. 
Manfaat dari e-Health sangat dirasakan pasien (ibu hamil) dan para orang tua pengguna layanan KIA yakni pelayanan menjadi lebih cepat, dengan sistem rujukan online masyarakat lebih dipermudah serta data-data pasien menjadi lebih akurat. Sistem pelaporan menjadi juga lebih cepat, jumlah masyarakat yang bisa dilayani menjadi lebih banyak dibandingkan dengan metode yang masih manual. Hal ini menunjukkan peningkatan pada aspek keandalan sebagai salah satu variabel kualitas pelayanan.

Faktor pendukung dalam penerapan e-Health atau Simpus di Puskesmas Mantrijeron secara internal dari SDM-nya yang memiliki keterampilan dan pengetahuan yang memadai utamanya dalam menggunakan Simpus ataupun perangkat komputer, pengetahuan perawatan jaringan, selain itu dukungan dari pimpinan dalam hal ini kepala Puskesmas juga memberikan kontribusi bagi Puskesmas Mantrijeron. Untuk faktor eksternal, Dinas Kesehatan Kota Yogyakarta, serta Dinas Komunikasi Informatika dan Persandian juga memberikan kemudahan dalam mendukung pengembangan e-Health atau Simpus. Adapun Faktor penghambat dalam penerapan e-Health adalah kuantitas SDM utamanya di bagian kasir belum memadai secara kuantitas, faktor jaringan yang seringkali eror sehingga menghambat dalam pelaksanaan tugastugas.

\section{DAFTAR PUSTAKA}

Amabile, T.M. 1993. Motivational Synergy: Toward New Conceptualizations of Intrinsic and Extrinsic Motivation in the Workplace. Human Resource Management Review. 3. 185-201

Idrus, Muhammad. 2009. Metode Penelitian Ilmu Sosial. Yogyakarta: Erlangga.

Inasari Widiyastut. 2008. Analisa Aplikasi E-Health Berbasis Website di Instansi Kesehatan Pemerintah dan Swasta serta Potensi Implementasinya di Indonesia. Jurnal Penelitian Ilmu Pengetahuan dan Teknologi Komunikasi. Volume 10 Nomor 2, Desember.

IKCI. (2015, Juli 16). Kota Yogyakarta: Inovasi untuk Menjawab Tantangan. 15 Oktober 2016. ipsus.kompas.com/kotacerdas/

Winarno, Budi. 2007. Kebijakan Publik Teori dan Proses. Jakarta: Media Presindo.

Wahab, Solichin A. 2005. Analisis Kebijaksanaan: Dari Formulasi ke Implementasi.

$\begin{array}{ccc}\text { KepMenKes } & \text { Nomor } & \text { 192/MEN- } \\ \text { KES/SK/VI/2012. } & \end{array}$

Profil Kesehatan Tahun 2015 Kota Yogyakarta (Data Tahun 2014). 